\title{
GESTÃo SOCIOAMBIENTAL EM PEQUENAS E MÉDIAS EMPRESAS
}

\author{
Marcelo Augusto Viana Pereira ${ }^{1}$ \\ Marcia Athayde Moreira ${ }^{2}$ \\ Cyntia Meireles Martins ${ }^{3}$ \\ Bruna Vaz da Costa de Moura ${ }^{4}$
}

\begin{abstract}
RESUMO
As pequenas e médias empresas - PMEs são desafiadas a buscar soluções que promovam o crescimento econômico sem perder de vista a sociedade e o meio ambiente. Neste contexto, a pesquisa teve como objetivos identificar como ocorre a gestão socioambiental em pequenas e médias empresas, realizando associações entre o perfil dos entrevistados e suas práticas. Foi realizada uma pesquisa de natureza quantitativa de caráter descritivo e exploratório, baseada no resultado obtido em pesquisa de campo promovida junto a gestores de empresas enquadradas como PMEs. As análises mostraram que as PMEs realizam a implementação de programas de capacitação profissional, programas de bonificação e o fornecimento de auxílio refeição aos colaboradores, assim como realizam ações para a economia de energia elétrica e de água, o estímulo ao uso de caneca e a coleta seletiva de lixo. Foram observadas a influência do cargo exercido e do tempo de atuação sobre as ações socioambientais. Conclui-se que a gestão socioambiental pode ser utilizada como instrumento de aperfeiçoamento para PMEs e que, no campo da ciência, é relevante e inovador desenvolver e divulgar pesquisas para as organizações, empreendedores, gerentes e colaboradores, para que a temática socioambiental possa cada vez mais fazer parte do dia a dia dos cidadãos e, assim, possam transcender os muros das organizações, chegando também às comunidades, aos clientes, fornecedores e demais stakeholders.
\end{abstract}

Palavras-chave: Empreendedorismo. Gestão socioambiental. Pequenas e médias empresas. Stakeholders.

\section{SOCIAL AND ENVIRONMENTAL MANAGEMENT IN SMES}

\begin{abstract}
Small and medium-sized companies - SMEs are challenged to seek solutions that promote economic growth without losing sight of society and the environment. In this context, the research aimed to identify how social and environmental management takes place in small and medium-sized companies, making associations between the profile of respondents and their practices. A descriptive and exploratory quantitative research was carried out, based on the results obtained in field research promoted with managers of companies classified as SMEs. The analyzes showed that SMEs carry out the implementation of professional training programs, bonus programs and the provision of meal allowances to employees, as well as carry out actions to save electricity and water, encourage the use of mugs and collection selective garbage. The influence of the position held and the length of experience on social and environmental actions were observed. It is concluded that socio-environmental management can be used as an instrument of improvement for SMEs and that, in the field of science, it is relevant and innovative to develop and disseminate research for organizations, entrepreneurs, managers and employees, so that the socio-environmental theme can increasingly more part of the daily lives of citizens and thus can transcend the walls of organizations, reaching communities, customers, suppliers and other stakeholders as well.
\end{abstract}

Keywords: Entrepreneurship. Small and medium companies. Social and environmental management. Stakeholders.

\footnotetext{
${ }^{1}$ Mestre em Administração Gestão Organizacional pela Universidade da Amazônia - UNAMA, Pará, (Brasil). Professor na Faculdade Pan Amazônica - FAPAN, Pará. http://orcid.org/0000-0002-9238-3760 E-mail: $\underline{\text { mv_contador@hotmail.com }}$

${ }^{2}$ Pós-Doutora em Administração Estratégica e Empreendedorismo pela Escola de Administração de Empresas de São Paulo da Fundação Getúlio Vargas EAESP/FGV, São Paulo, (Brasil). Professora e pesquisadora do Programa de Mestrado e Doutorado em Administração da Universidade da Amazônia - UNAMA, Pará, (Brasil). E da Universidade Federal do Pará - UFPA, Pará. https://orcid.org/0000-0003-1859-6394 E-mail: mathayde@ufpa.br

${ }^{3}$ Doutora em Ciências Agrárias pela Universidade Federal Rural da Amazônia - UFRA, Pará, (Brasil). https://orcid.org/0000-0002-5695-8504 E-mail: cyntiamei@ hotmail.com

${ }^{4}$ Graduação em Ciência Contábeis pela Universidade Federal do Pará - UFPA, Pará, (Brasil). https://orcid.org/00000003-4892-8855 E-mail: bruna.moura@icsa.ufpa.br
} 


\section{INTRODUÇÃO}

Consolidado o entendimento de que a promoção do desenvolvimento das organizações é elemento indissociável dos aspectos social, econômico e ambiental (Bossle, 2008), a pressão que antes pesava apenas sobre grandes organizações se capilarizou para pequenas e médias empresas PMEs (Cordano, Marshall \& Silverman, 2010; Font, Garay, \& Jones, 2016, Yacob \& Khor, 2019). Nesse contexto, pequenas organizações também vêm passando a sentir a pressão para promover o desenvolvimento atrelado à gestão socioambiental. Nesse sentido, Aligleri e Prevideli (2001), Passos e Camara (2003), Karkotli, Ferreira e Souza (2005), Nogueira (2012), Sanches e Schimidt (2016), Schott e Vasconcelos (2019), Santos, Silva e Caetano (2020) demonstraram, por meio de pesquisas, que, embora os pequenos empreendedores já demonstrem a preocupação com a realização de uma gestão socioambiental, as práticas ainda são desenvolvidas de forma não sistemática; sendo que a gestão ambiental e social ainda é uma realidade distante de ser realizada na maioria das organizações de pequeno porte.

Complementando o entendimento, Martins, Escrivão Filho e Nagano (2015), Paiva e Giesta (2019), Bakos, Siu, Orengo e Kasiri (2019) e Lopes e Barbosa (2021) evidenciaram resultados que contrariam o pessimismo da literatura sobre a existência de boas práticas socioambientais em PMEs, observando a necessidade de avaliar a gestão socioambiental empresarial sobre novos paradigmas, superando um enfoque limitado à realidade das grandes empresas e considerando, por sua vez, as especificidades de gestão das PMEs no que tange, por exemplo, à cultura e às limitações operacionais e financeiras.

É nítido que as pequenas e médias empresas apresentam grandes dificuldades para se manterem no mercado (Sammut, 2001). A falta de recursos financeiros, a dependência de crédito bancário e a escassez de outros recursos, como tecnologia e recursos humanos, são dificuldades que as PMEs enfrentam no dia a dia para continuarem suas atividades operacionais (Walsh, White \& Dowell, 1981; Deitos, 2002). Para empresas que já enfrentam problemas de toda ordem para se manterem ativas no mercado, a gestão socioambiental torna-se mais um elemento de gerenciamento dos recursos da empresa; exigindo que seja articulada por meio de ações simples e com percepção de custo-benefício; não precisa ser complexa e nem exigir grandes investimentos; mas exige mudança de mentalidade entre os seus gestores (Walsh, White \& Dowell, 1981; Santos, Silva \& Caetano, 2019; Bakos et al., 2020).

Assim, fato é que a implantação e a utilização de diretrizes ambientais e sociais nas PMEs brasileiras devem refletir suas relações com seus stakeholders (Freeman, 1984), atendendo, de forma equilibrada, os interesses da empresa com dos demais agentes com quem se relaciona. Tudo isso em um contexto de responsabilidade socioambiental, mantendo os aspectos econômicofinanceiros e de competitividade em foco.

Neste cenário, destaca-se a importância da gestão socioambiental para a sociedade e a necessidade de que todas as organizações a adotem como ferramenta de gestão, independentemente do porte, com ênfase especial no incentivo a que pequenas e médias empresas se engajem em ações de responsabilidade socioambiental. Diante do exposto, é estabelecida a seguinte questão que norteará esta pesquisa: como a gestão socioambiental está sendo empregada nas pequenas e médias empresas?

Como objetivo, esta pesquisa visa identificar como está sendo empregada a gestão socioambiental em pequenas e médias empresas, realizando associações entre o perfil dos entrevistados e levantando as práticas e as percepções sobre a gestão socioambiental que praticam.

Justifica-se esta pesquisa, na medida em que se torna clara a necessidade de se promover mudanças, desenvolvendo abordagens destinadas a lidar com crises ambientais e com uma nova postura interessada em interagir com empresas éticas, com imagem institucional positiva e que atuem de forma ecologicamente responsável (Tachizawa, 2010), compreendendo que o processo de amadurecimento da gestão socioambiental perpassa pelo entendimento de que o meio-ambiente é prioritário e que a sua proteção, em vez de obstáculo, será, no longo prazo, mola propulsora ao 
desenvolvimento econômico, particularmente em uma economia em desenvolvimento, como o Brasil, onde o desenvolvimento industrial e a sustentabilidade ambiental integrada são etapas fundamentais do desenvolvimento econômico (Tenório, 2006; Yacob, Wong \& Khor, 2019).

A gestão socioambiental precisa ser pensada por todos, com necessidade de amplo engajamento de todos os setores, destacando a academia, onde novos estudos são recorrentes e nesse contexto, destaca-se um campo fértil para o estudo das práticas socioambientais entre PMEs brasileiras. No Brasil, pequenas e médias empresas representam 98,5\% do total de empresas privadas brasileiras, respondendo por $27 \%$ do PIB e por $54 \%$ do total de empregos formais existentes no país (Sebrae, 2018), são reconhecidas como a espinha dorsal de qualquer economia, pois contribuem significativamente para o emprego e o crescimento econômico (Agnelli, 2017; Yacob \& Khor, 2019). No entanto, estudos (Barbosa \& Teixeira, 2001; Arruda, 2016; Santos, Silva \& Caetano, 2020) demonstram que pequenas empresas não se percebem como poluidoras, desconhecendo, muitas vezes, a forma de colocar em prática ações de natureza socioambiental. Dessa forma, ao promover o debate sobre o tema, expandindo o entendimento e engajando o cidadão nessa luta de proteção do futuro do planeta, gerando informações úteis para oferecer subsídios e auxílio na elaboração e revisão de políticas públicas atinentes ao tema sustentabilidade para pequenas empresas.

\section{GESTÃO SOCIOAMBIENTAL NAS PEQUENAS E MÉDIAS EMPRESAS}

Nos últimos 50 anos, verifica-se que os recursos naturais são insumos nos processos de produção, em especial para as empresas industriais. Nesse cenário, grandes passos foram dados em direção à consolidação de práticas e à formulação de diretrizes que tratam a questão ambiental de forma sistêmica e interligada (Tinoco \& Kraemer, 2011), abrangendo todos os empreendimentos: com fins lucrativos, sociais, públicos, privados, grandes e pequenos.

Em se tratando de grandes empresas, cumpre destacar que, a cada dia, as organizações vêm melhorando e adequando as suas práticas de acordo com os sistemas de gestão ambiental (Aghelie, 2017), aderindo às certificações ambientais e, com isso, exigindo de suas cadeias de fornecedores a mesma postura (Pereira, Melo, Slomski \& Weffort, 2013). Diante desse fato, é possível afirmar que, para as pequenas e médias empresas, não será diferente se quiserem permanecer no mercado.

A percepção e a realidade do desempenho em responsabilidade socioambiental podem influenciar nos seguintes fatores: na sua vantagem competitiva, na reputação, na percepção de investidores, na capacidade de atrair e manter trabalhadores, na relação com empresas, governo, fornecedores, clientes e sociedade (Yacob \& Khor, 2019). Dessa forma, grandes são as vantagens para as organizações e, principalmente, aquelas que estão enquadradas como pequenas e médias empresas.

No entendimento de Donaire (1995), o que permitiu que várias pequenas e médias empresas iniciassem a reformulação de suas estratégias organizacionais foi o crescimento da consciência ecológica, na sociedade, no governo e nas próprias empresas, que passaram a incorporar essa orientação em suas estratégias. Com a inclusão das pequenas e médias empresas no cenário social e ambiental, essas organizações passam a ser as grandes responsáveis pelo crescimento das economias locais, pois são grandes geradores de emprego e distribuição de renda (Ferronato, 2011), mas, ao mesmo tempo, demonstram grande potencial poluidor (Aghelie, 2017).

Logo, a implantação e a utilização de diretrizes ambientais e sociais nas PMEs brasileiras devem refletir as relações das PMEs e os seus stakeholders (Freeman, 1984), atendendo, de forma equilibrada e em um contexto de responsabilidade socioambiental, os interesses das empresas e dos demais agentes com quem se relacionam, mantendo sempre os aspectos econômico-financeiros e de competitividade em foco. Por outro lado, para os empresários das pequenas empresas, a gestão socioambiental ainda parece ser um tema distante, muito embora atual, notadamente na realidade brasileira (Demajorovic \& Santiago, 2011; Sanches e Schimidt (2016); Schott e Vasconcelos (2019); Santos, Silva \& Caetano, 2020). 
Estudos realizados no Brasil, tais como o de Aligleri e Prevideli (2001), Passos e Camara (2003), Karkotli, Ferreira e Souza (2005), Nogueira (2012), e Sanches e Schimidt (2016), Schott e Vasconcelos (2019), Santos, Silva e Caetano (2020), e realizados no exterior (Font, Garay \& Jones, 2016; Yacob \& Khor, 2019; Bakos et al., 2020) que envolvem práticas de gestão socioambiental, identificam que, embora os pequenos empreendedores já demonstrem a preocupação com a adoção de uma gestão socioambiental, se limitam à realização não sistemática de algumas práticas socioambientais, um desafio, portanto, para internalizar nos empresários desse segmento a consciência diária da sustentabilidade.

Moysés Filho, Rodrigues e Moretti (2011) argumentam que a gestão social e ambiental, em especial em pequenas e médias empresas, deve considerar as relações entre os seus stakeholders interno e externos, compatibilizando necessidades e particularidades a cada público. A gestão de stakeholders, inclusive, é compreendida por Martins, Escrivão Filho e Nagano (2015) e ressaltada na pesquisa de Font, Garay e Jones (2016) como indiscutível facilitador da implantação da gestão ambiental em pequenas e médias empresas, sobretudo pela flexibilidade desse segmento em gerenciar seus relacionamentos intra e extraorganizacionais.

Pela importância do papel desempenhado pelas PMEs no Brasil e em todo mundo, organizações desse porte devem ser estimuladas à realização de gestão socioambiental. Nesse sentido, quatro aspectos sobre a gestão socioambiental são destacados: (I) a realização de práticas de gestão socioambiental pelas empresas; (II) a percepção dos empreendedores sobre a importância da adoção de práticas de gestão socioambiental; (III) as vantagens econômicas decorrentes da adoção de práticas de gestão socioambiental; e, (IV) políticas de incentivos a adoção de práticas de gestão socioambiental (Pereira \& Moreira, 2018). Esta categorização de estudos, identificada por meio de bibliometria, permitiu identificar, em cada grupo, algumas das principais práticas de gestão socioambiental, realizadas por pequenas empresas no Brasil.

\subsection{Realização de práticas de gestão socioambiental pelas PMEs}

Pesquisas de Aligleri e Prevideli (2001), Passos e Camara (2003), Karkotli, Ferreira e Souza (2005), Nogueira (2012), Sousa, Silva, Rabelo Neto e Sousa (2014), Sanches e Schimidt (2016), Paiva e Giesta (2019), Schott e Vasconcelos (2019), Yacob e Khor (2019) e Santos, Silva e Caetano (2020) destacam como resultado um ponto em comum: a ausência de estratégias formais de ações de responsabilidade socioambiental, assim como sua adoção sistemática; as ações, embora estejam evoluindo, são realizadas de forma não sistemática. Assim, pode-se afirmar que existem iniciativas de sustentabilidade ambiental, principalmente no que tange aos ecossistemas água e uso de recursos; os empreendedores estão se preocupando com as questões de sustentabilidade ambiental; e, os pequenos empreendedores, ainda que pese certa consciência sobre sustentabilidade, ainda carecem de organização, disciplina, conscientização e comprometimento para alcançar melhores resultados.

Dentre as práticas de gestão socioambiental, destacam-se aquelas de menor impacto financeiro para sua implantação, pois, embora o tema esteja em foco e grandes empresas a pratiquem, ainda é um assunto pouco explorado e difundido entre as PMEs. Registre-se, ainda, que algumas práticas são de cunho obrigatório movidas por legislações ambientais e outras são realizadas em razão de seu baixo custo de implantação (Demajorovic \& Santiago, 2011).

De acordo com Demajorovic e Santiago (2011), em pesquisa realizada pelo Sebrae com 385 MPEs, $31 \%$ das empresas declararam conhecer os impactos que podem causar ao meio ambiente, e afirmam que já realizaram alguma ação para minimizar esse impacto. A mesma pesquisa apontou também que $21 \%$ das empresas pesquisadas declararam conhecer o impacto que provocam no meio ambiente, porém nada realizam para minimizá-lo, e $48 \%$ restantes não conhecem o impacto ambiental que geram e dentre as práticas socioambientais mais adotadas estão a economia de energia e água com $61 \%$ das empresas pesquisadas, resultado que se coaduna com as pesquisas de Font, Garey e Jones (2016), Paiva e Giesta (2019) e Santos, Silva e Caetano (2020), Yacob \& Khor 
(2019) que observaram que as práticas ambientais mais recorrentes são voltadas à de economia de energia e água, alguns realizando a coleta seletiva e o reaproveitamento de materiais.

Entre práticas de gestão social, destacam-se o fornecimento de vale refeição e/ou alimentação, o auxílio educacional, o auxílio-creche, plano de saúde, capacitação dos colaboradores e sensibilidade aos portadores de deficiência, entre outras ações (Demajorovic \& Santiago; 2011; Paiva \& Giesta, 2019; Silva, Theis, Schreiber \& Figueiro, 2020), além da realização de ações sociais junto à comunidade (Silva, Santos \& Caetano, 2020).

\subsection{Percepção dos proprietários-gerentes sobre a importância da adoção de práticas de gestão socioambiental}

A respeito da percepção dos empreendedores sobre a importância da adoção de práticas de gestão socioambiental, destacam-se os artigos de Barbosa e Teixeira (2001), Arruda (2016), Santos, Silva e Caetano (2019) segundo os quais pequenos empresários não se percebem como poluidores, não acreditam que o impacto causado pelos pequenos negócios não necessita ser gerenciado e desconhecem a forma de colocar em prática ações de natureza socioambiental, o que torna ainda mais desafiador internalizar a consciência de sustentabilidade no dia a dia dos empreendedores.

Nesta perspectiva, é relevante investigar a perspectiva do alinhamento entre gestão ambiental e estratégia empresarial, pois essa relação está diretamente associada a uma gestão ambiental proativa (Martins, Escrivão \& Nagano, Yacob \& Khor, 2015). Shuman, Shaw e Sussman (1985) observaram, ainda na década dos anos oitenta, que os dirigentes das PMEs não são engajados com planejamento estratégico e que o planejamento é feito baseando-se em problemas, dando ênfase aos resultados de curto prazo, fato que prejudicaria a gestão socioambiental em uma organização, dado seu caráter de longo prazo. Os autores reforçam que a gestão proativa e sistêmica sobre as questões ambientais traz maior possibilidade de conciliar ações direcionadas para melhoria do meio ambiente ao mesmo tempo em que conseguem auferir maiores resultados econômicos e financeiros, decorrentes de ações ambientalmente corretas.

É nesse contexto que se destaca o nível de importância que as PMEs estão dando às práticas socioambientais como um elemento fundamental à inclusão da gestão socioambiental como estratégia nas PMEs, e nesse sentido os resultados atuais não são unânimes, tendo sido encontradas pesquisas que apontam para a atribuição de importância à gestão socioambiental (Paiva \& Giesta, 2019; Lopes \& Barbosa, 2021) e pesquisas que sinalizam na direção contrária (Stumpf, Theis \& Schreiber, 2018, Santos, Silva \& Caetano, 2020).

Dessa forma, observa-se que, embora as práticas de gestão socioambiental para PMEs não sejam obrigatórias, é um tema que requer atenção por parte dos pequenos empreendedores e o reflexo dessas ações serão percebidas no médio e longo prazo.

\subsection{Vantagens econômicas decorrentes da adoção de práticas de gestão socioambiental}

Para Savitz (2007), a responsabilidade socioambiental é definida como sendo aquela que gera lucro para seus acionistas, ao mesmo tempo em que protege o meio ambiente e melhora a qualidade de vida das pessoas com quem mantém relações. Nesse sentido, pode-se destacar as pesquisas de Trindade (2012), Scharf, Orlandi e Fernandes (2013), Oliveira e Rosseto (2014), Martins, Escrivão Filho e Nagano (2015), Salvia, Pilonetto e Brandli (2016), Font, Garay e Jones (2016), Aghelie (2017), Bakos et al., (2019) as quais evidenciaram que a implantação da gestão ambiental passou a ser um componente estratégico na redução dos custos e busca de eficiência, e utilizada estrategicamente para a melhora da imagem organizacional. A questão competitividade também foi mencionada como elemento de estímulo para a adoção de estratégias de gestão socioambiental pelas empresas (Aghelie, 2017; Bakos et al., 2019).

Ademais, pesquisas apontam que ações ambientais e sociais, quando inseridas no processo estratégico da organização, passam a ser de significativa importância para desenvolver respostas a 
desafios impostos pelos stakeholders (Yacob \& Khor, 2019). Para Sanches (2000), a formalização dessas práticas socioambientais, não é somente para divulgar que a empresa está envolvida em buscar soluções ambientais e sociais, mas de encorajar um maior comprometimento de todos na organização.

Este comprometimento com a gestão socioambiental permite uma facilidade no processo de gerenciamento e, com isso, são capazes de melhorar o seu desempenho, obtendo vantagens econômicas, de imagem e competitividade (Kraemer, 2008; Aghelie, 2017; Paiva \& Giesta, 2019; Bakos et al., 2019), tais como economia de custos; reciclagem, venda e aproveitamento de resíduos e diminuição de efluentes; redução de multas e penalidades por poluição; incremento de receita; aumento da participação no mercado, devido à inovação dos produtos e à menor concorrência; e aumento da demanda para produtos que contribuam para a diminuição da poluição; melhoria da imagem institucional; renovação da carteira de produtos; aumento da produtividade; melhoria da criatividade para novos desafios; acesso assegurado ao mercado externo e melhor adequação aos padrões ambientais.

O uso de práticas de gestão socioambiental nas organizações é um caminho em que as PMEs podem se fundamentar para obter melhores planejamentos e gerenciamento dos recursos, a fim de inserir a organização em um seleto grupo de empresas que pensam e praticam ações ambientais e sociais, com vistas a atender seus objetivos e dos demais stakeholders que se relacionam com a organização.

\subsection{Políticas de incentivo a adoção de práticas de gestão socioambiental}

Entre as políticas de incentivo, pode-se destacar Seravalli (2018), o qual chama atenção para os 17 objetivos de desenvolvimento sustentável (ODS) propostos em setembro de 2015 pela Organização das Nações Unidas em conjunto com líderes mundiais. Como resultado, foi elaborada a Agenda 2030 para o desenvolvimento sustentável, que, segundo o autor, trilha o caminho para o futuro e demanda a contribuição de todos os setores da sociedade e do mercado, inclusive, pequenas e médias empresas. Como se vê, trata-se de objetivo voltado à integração do desenvolvimento econômico ao bem-estar social e ao estímulo de tecnologias e processos limpos e ambientalmente sustentáveis.

Em outro caminho, o Sebrae (2015) elenca alguns incentivos governamentais às pequenas empresas com foco para sustentabilidade: redução ou isenção de impostos; tributação conforme critérios ambientais; e incentivos em infraestrutura, como doação de terrenos. Aliás, o Sebrae (2015) destaca que, de um modo geral, o Brasil ocupa a $18^{a}$ posição entre os países que mais utilizam impostos como incentivos para sustentabilidade. Nesse contexto, como exemplo prático dos incentivos governamentais à sustentabilidade, cita-se o IPTU verde, de caráter municipal, que oferece descontos para empresas com soluções sustentáveis em seus imóveis ou o PROINFA (Lei $\mathrm{n}^{\circ} .10 .438 / 2002$ ), cujo objetivo consiste em fomentar o uso de fontes alternativas de energia.

Assim, de um modo geral, os autores obtiveram como resposta que a geração de uma cultura organizacional de comprometimento de todos os colaboradores da organização é muito importante para que sejam realizadas ações socioambientais na organização. Nesse sentido, os resultados das pesquisas apontam que tem havido evolução nas ações de natureza socioambiental entre as micros e pequenas empresas, as quais contribuem positivamente para melhorar a imagem da organização e acrescentando-lhe um diferencial competitivo (Aligleri \& Prevideli, 2001; Passos \& Camara, 2003; Karkotli et al., 2005, Sousa et al., 2014; Sanches \& Schimidt, 2016; Aghelie, 2017; Paiva \& Giesta, 2019; Bakos et al, 2019).

\section{MÉTODOLOGIA UTILIZADA}

Para a definição da metodologia, toma-se como base a classificação de pesquisa apresentada por Farias Filho e Arruda Filho (2013). Trata-se de pesquisa com abordagem exploratória e 
descritiva, realizada por meio de levantamento, em corte transversal, utilizando-se para isso um questionário estruturado. A Figura 1 apresenta, de forma sumarizada, o desenho da pesquisa.

O questionário aplicado, enquanto instrumento de coleta de dados, foi do tipo fechado com escala numérica de Likert. Para a sua aplicação, foi utilizado o método websurvey, consistente na aplicação de questionário on line com a possibilidade de envio por Internet, facebook, whatsapp e outras mídias sociais do link apropriado para preenchimento pelos respondentes, amplamente encaminhado para empreendedores por meio de redes sociais ou aplicado diretamente pelos pesquisadores, durante os meses de outubro de 2019 a março de 2020. Foi elaborado contendo três blocos de questões, assim aplicadas: o primeiro bloco de questões foi destinado à coleta de dados sociodemográficos, questionamento a idade, o nível de escolaridade, o cargo e/ou função desempenhado na empresa e o tempo de atuação na função de que desempenha, tendo sido questionado ainda qual o segmento da empresa, a cidade/estado em que se localiza e o número total de colaboradores.

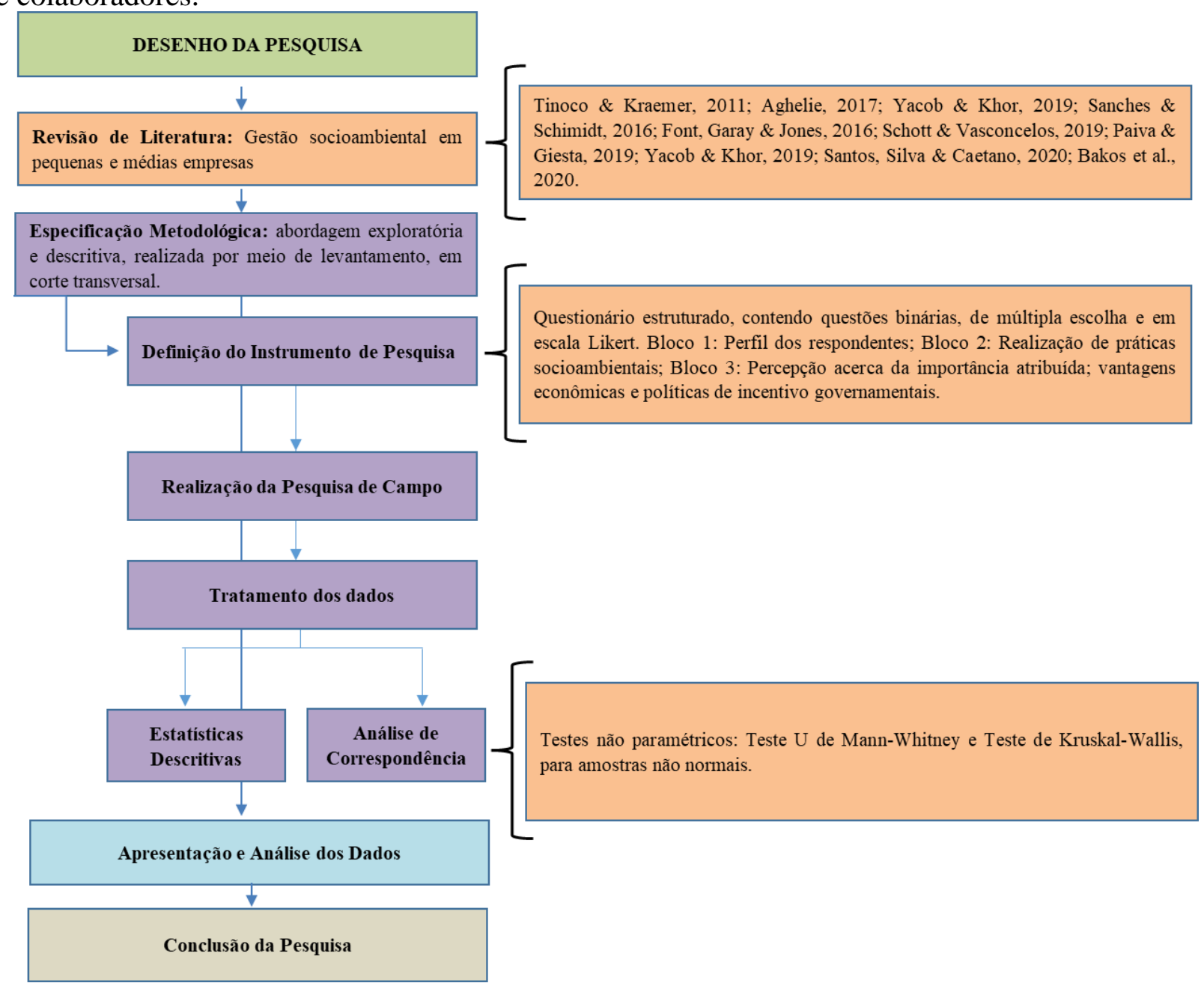

Figura 1. Desenho da pesquisa

Fonte: Elaborado pelos autores (2020)

O segundo bloco de questões se dedicou a capturar a realização de práticas de gestão socioambiental, com a especificação de 17 questões binárias do tipo SIM/NÃO, listando atividades socioambientais, as quais foram observadas na literatura estudada, sendo apresentadas na Tabela 1. 
Tabela 1. Especificação das práticas de gestão socioambientais

\begin{tabular}{|l|l|}
\hline Item & Práticas de gestão socioambiental \\
\hline 01 & Fornecimento de auxílio refeição. \\
\hline 02 & Fornecimento de auxílio educação. \\
\hline 03 & Capacitação e desenvolvimento profissional. \\
\hline 04 & Concessão de creche ou auxílio creche para os filhos dos colaboradores. \\
\hline 05 & Fornecimento de auxílio saúde \\
\hline 06 & Programa de contratação de colaboradores com necessidades especiais - PNEs. \\
\hline 07 & Programa de bonificação dos colaboradores. \\
\hline 08 & Programa de ginástica laboral. \\
\hline 09 & Ações sociais junto à comunidade local. \\
\hline 10 & Coleta seletiva de lixo. \\
\hline 11 & Economia de energia elétrica. \\
\hline 12 & Economia de água ou canalização de água da chuva na limpeza da empresa. \\
\hline 13 & Uso de papel reciclado. \\
\hline 14 & Fornecimento/estímulo ao uso de caneca para beber água/cafezinho. \\
\hline 15 & Cursos de educação ambiental para os colaboradores. \\
\hline 16 & Uso de suprimento de informática recarregável \\
\hline 17 & Aproveitamento de resíduos sólidos gerados pela empresa \\
\hline
\end{tabular}

Fonte: Elaborado pelos autores (2020).

O terceiro bloco de questões foi dedicado a levantar informações acerca da percepção da importância atribuída à adoção de práticas de gestão socioambiental; das vantagens econômicas decorrentes da adoção de práticas de gestão socioambiental; e a percepção sobre as políticas de incentivo à adoção de práticas de gestão socioambiental em PMEs, conforme apresentado nas Tabelas de 1 a 3.

Tabela 2. Importância atribuída à adoção de práticas de gestão socioambiental

\begin{tabular}{|c|c|c|}
\hline Categorias de análise & Assertivas & Autores \\
\hline \multirow{5}{*}{$\begin{array}{l}\text { Categoria } 1 \\
\text { Importância atribuída à } \\
\text { adoção de práticas de } \\
\text { gestão socioambiental }\end{array}$} & $\begin{array}{l}\text { É importante que pequenas e médias empresas } \\
\text { desenvolvam práticas de gestão socioambiental. }\end{array}$ & $\begin{array}{l}\text { Barbieri (2007); Andrade, } \\
\text { Tachizawa e Carvalho (2002) }\end{array}$ \\
\hline & $\begin{array}{l}\text { Pequenas e médias empresas estão cada vez mais } \\
\text { preocupadas, não só com resultados financeiros (lucro), } \\
\text { mas também com a sociedade e o meio ambiente. }\end{array}$ & $\begin{array}{l}\text { Passos e Camara (2003); } \\
\text { Sanches e Schimidt (2016). }\end{array}$ \\
\hline & $\begin{array}{l}\text { Os empreendedores não se reconhecem como agentes } \\
\text { poluidores do meio ambiente. }\end{array}$ & Barbosa e Teixeira (2001). \\
\hline & $\begin{array}{l}\text { A gestão social e ambiental, em especial em pequenas e } \\
\text { médias empresas, deve considerar as relações entre os seus } \\
\text { stakeholders internos e externos, compatibilizando } \\
\text { necessidades e particularidades a cada público. }\end{array}$ & $\begin{array}{l}\text { Moysés Filho, Rodrigues e } \\
\text { Moretti (2011). }\end{array}$ \\
\hline & $\begin{array}{l}\text { Gestão socioambiental é tão importante para a } \\
\text { sustentabilidade em longo prazo dos negócios, como a } \\
\text { gestão financeira. }\end{array}$ & $\begin{array}{l}\text { Barbieri (2007); Andrade, } \\
\text { Tachizawa e Carvalho (2002). }\end{array}$ \\
\hline
\end{tabular}

Fonte: Elaborado pelos autores (2020)

Tabela 3. Vantagens econômicas decorrentes da adoção de práticas de gestão socioambiental

Categorias de análise

\section{Categoria 2}

Vantagens econômicas decorrentes da adoção de práticas de gestão socioambiental
Assertivas

É possível que as pequenas empresas desenvolvam práticas de gestão socioambiental sem comprometer os lucros da empresa.

A prática de gestão socioambiental melhora a imagem da empresa perante os seus clientes, facilitando assim a fidelização, conquista de novos clientes e o aumento das vendas

Práticas de gestão socioambiental geram alguns benefícios econômicos, tais como a redução de água, energia, entre outros insumos.

Produtos ecologicamente corretos, estão sendo cada vez mais procurados pelos consumidores.

A gestão de negócios sem consciência ambiental provocará perda de oportunidades em mercados em rápido crescimento.

\begin{tabular}{|c|}
\hline Autores \\
\hline $\begin{array}{l}\text { Aligleri; } \quad \text { Prevideli } \\
(2001)\end{array}$ \\
\hline $\begin{array}{l}\text { Demajorovic; } \\
\text { Santiago (2011) }\end{array}$ \\
\hline $\begin{array}{l}\text { Demajorovic; } \\
\text { Santiago (2011) }\end{array}$ \\
\hline $\begin{array}{l}\text { Andrade, Tachizawa } \\
\& \text { Carvalho (2002) }\end{array}$ \\
\hline
\end{tabular}

Tachizawa (2010)

Fonte: Elaborado pelos autores (2020) 
Tabela 4. Políticas de incentivo à adoção de práticas de gestão socioambiental em PMEs

\begin{tabular}{|c|l|l|}
\hline Categorias de análise & \multicolumn{1}{|c|}{ Assertivas } & \multicolumn{1}{|c|}{ Autores } \\
\hline & $\begin{array}{l}\text { Os governos federal, estaduais e municipais devem desenvolver } \\
\text { políticas de incentivos as pequenas empresas que adotarem } \\
\text { práticas de gestão socioambiental. }\end{array}$ & Barbosa e Teixeira (2001) \\
\cline { 2 - 4 } $\begin{array}{c}\text { Percebo no meu estado e na minha cidade, legislação específica } \\
\text { para que as PMEs pratiquem ações ambientais e sociais. }\end{array}$ & Lei 123/2006 \\
\cline { 2 - 4 } $\begin{array}{c}\text { Política de incentivos a } \\
\text { adoção de práticas de } \\
\text { gestão socioambiental }\end{array}$ & $\begin{array}{l}\text { A Lei Geral das Micro e Pequenas empresas (Lei 123/2006) } \\
\text { concede benefícios econômicos e sociais, sem exigir que as } \\
\text { empresas desenvolvam e pratiquem ações socioambientais. }\end{array}$ & Lei 123/2006 \\
\cline { 2 - 4 } & $\begin{array}{l}\text { A redução de impostos ou alíquotas diferenciadas é uma boa } \\
\text { política de incentivo para adoção de práticas de gestão } \\
\text { socioambiental. }\end{array}$ & Sebrae (2015) \\
\cline { 2 - 4 } & $\begin{array}{l}\text { Os incentivos tributários, concedidos as PMEs permitem o } \\
\text { desenvolvimento de práticas de gestão socioambiental. }\end{array}$ & Lei 123/2006 \\
\hline
\end{tabular}

Fonte: Elaborado pelos autores (2020)

A cada item foi atribuída uma escala como segue: concordo totalmente (5), concordo (4), neutro (3), discordo (2) e discordo totalmente (1). Para cada aspecto investigado, foram apresentadas cinco questões, totalizando 15 questões a serem respondidas.

Para atender aos objetivos desta pesquisa, foi utilizada amostragem não probabilística, iniciando-se a partir de network primário dos pesquisadores e de solicitação a cada respondente que indicasse novos potenciais empreendedores, os quais foram contactados por telefone, redes sociais e presencialmente, com vistas a ampliar a população a ser entrevistada.

O critério de inclusão de empresas nesta pesquisa precisava contemplar até 99 empregados no comércio e serviços, e até 499 empregados na indústria, conforme classificação preconizada pelo Serviço Brasileiro de Apoio às Micro e Pequenas Empresas (Sebrae, 2014). Ao final da pesquisa de campo, foram coletados 161 questionários válidos, compreendendo, assim, a amostra final desta pesquisa.

\subsection{Tratamento dos dados}

Inicialmente o tratamento dos dados foi realizado a partir de estatística descritiva, que permitiu identificar e mapear o perfil dos respondentes; conhecer as práticas de gestão socioambiental adotadas em suas organizações; evidenciar as percepções do empresário sobre a importância da Gsae e a possibilidade de obter retornos financeiros com a sua operacionalização na organização.

Após a realização das estatísticas descritivas, as informações geradas foram tratadas de forma a verificar se existe ou não relação entre as variáveis sociodemográficas e as variáveis de práticas de gestão socioambiental adotadas nas organizações, bem como as suas percepções sobre a importância da Gsae, e da possibilidade de obter retornos financeiros com a sua operacionalização na organização. Para tabulação, organização e análise dos dados coletados, foram utilizadas as ferramentas Excel ${ }^{\circledR}$ e Statistical Package for the Social Science (SPSS). A Tabela 5 apresenta a estrutura do estudo estatístico. 
Tabela 5. Estrutura das variáveis do estudo

\begin{tabular}{|c|c|c|}
\hline Grupo & Variável & Abordagem \\
\hline $\begin{array}{l}\text { Grupo } 01 \text { - Variáveis de } \\
\text { caracterização } \\
\text { sociodemográfica nas } \\
\text { PMEs }\end{array}$ & $\begin{array}{l}\text { Faixa etária do gestor da empresa (6 categorias); Nível de escolaridade } \\
\text { do gestor da empresa ( } 3 \text { categorias); Cargo/Função que desempenha na } \\
\text { Empresa ( } 2 \text { categorias); Tempo de atuação na função que desempenha } \\
\text { ( } 5 \text { categorias); Segmento do Empresa ( } 3 \text { categorias); } e \text {, Porte da } \\
\text { Empresa ( } 2 \text { categorias) }\end{array}$ & Qualitativas \\
\hline $\begin{array}{l}\text { Grupo } 02 \text { - Práticas de } \\
\text { gestão social nas PMEs }\end{array}$ & Porcentagem $(\%)$ de utilização das práticas sociais & Quantitativa \\
\hline $\begin{array}{ll}\text { Grupo } & \mathbf{0 3} \text { - Práticas de } \\
\text { gestão ambiental nas } \\
\text { PMEs }\end{array}$ & Porcentagem $(\%)$ de utilização das práticas ambientais & Quantitativa \\
\hline $\begin{array}{l}\text { Grupo 04: Dimensão de } \\
\text { percepção: importância } \\
\text { atribuída à adoção. }\end{array}$ & $\begin{array}{l}\text { Nível médio de concordância - Importância atribuída à adoção de } \\
\text { práticas de gestão socioambiental. }\end{array}$ & Quantitativa \\
\hline $\begin{array}{l}\text { Grupo 05: Dimensão de } \\
\text { percepção: } \quad \text { vantagens } \\
\text { econômicas decorrentes da } \\
\text { adoção. }\end{array}$ & $\begin{array}{l}\text { Nível médio de concordância - Vantagens econômicas decorrentes da } \\
\text { adoção de práticas de gestão socioambiental. }\end{array}$ & Quantitativa \\
\hline $\begin{array}{l}\text { Grupo 06: Dimensão de } \\
\text { percepção: política de } \\
\text { incentivos a adoção de } \\
\text { práticas. }\end{array}$ & $\begin{array}{l}\text { Nível médio de concordância - Política de incentivos a adoção de } \\
\text { práticas de gestão socioambiental. }\end{array}$ & Quantitativa \\
\hline
\end{tabular}

Fonte: Elaborado pelos autores (2020)

Foram criados, em cada uma das quatro categorias analisadas, um indicador que represente a categoria, delimitado por exemplo, pela porcentagem $(\%)$ de utilização das práticas sociais e ambientais, assim como foi criado um indicador global que represente cada uma das três dimensões de percepção de gestão socioambiental, condensando, pela média aritmética, o grau de concordância dos itens respondidos por cada empresa.

Para a análise de correspondência, foram utilizados testes não-paramétricos: o Teste U de Mann-Whitney (Teste não-paramétrico que substitui o Teste T-Student) e o Teste de Kruskal-Wallis (Teste não-paramétrico que substitui o Análise de Variância - Anova). Isso porque não foi detectada a normalidade dos dados para as variáveis quantitativas, de modo a inviabilizar a aplicação de um teste paramétrico (Teste t- Student e ANOVA).

\section{RESULTADOS E DISCUSSÕES}

O perfil predominante do respondente é o de um empreendedor localizado no município de Belém - Pará (96,3\% dos estabelecimentos), o qual possui uma pequena empresa $(97,5 \%)$ atuante no setor de comércio (73,3\%), jovem, com idade entre 26 e 45 (69,5\% da amostra), com nível médio completo (44,7\% das pessoas), o qual ocupa o cargo de gerente no empreendimento $(63,1 \%$ dos entrevistados), exercendo sua função a não menos que três anos a, ao máximo, de dez anos (50,9\% dos participantes).

\subsection{Realização de práticas de gestão socioambiental}

Para melhor compreensão, as práticas foram divididas em sociais e ambientais, organizandoas em ordem decrescente de realização e propondo uma análise descritiva a partir dos pontos positivos (em que ocorrem as práticas) para os pontos que necessitam de ajustes (em que não ocorrem as práticas). A Figura 2 apresenta, em ordem decrescente de percentuais, as práticas sociais mais utilizadas pelas empresas entrevistadas. Destaca-se a ação de responsabilidade social com maior efetividade entre os empreendedores: a capacitação e o desenvolvimento profissional, com $76,4 \%$ de ocorrência. Fornecer treinamento no local de trabalho relaciona-se à obtenção da 
qualidade nos bens e serviços oferecidos pelas empresas, é possível afirmar que tal prática é adotada entre as PMEs para melhorar a qualidade nos bens e serviços por elas oferecidos, como também observado nas pesquisas de Paiva e Giesta (2019) e Silva et al. (2020).

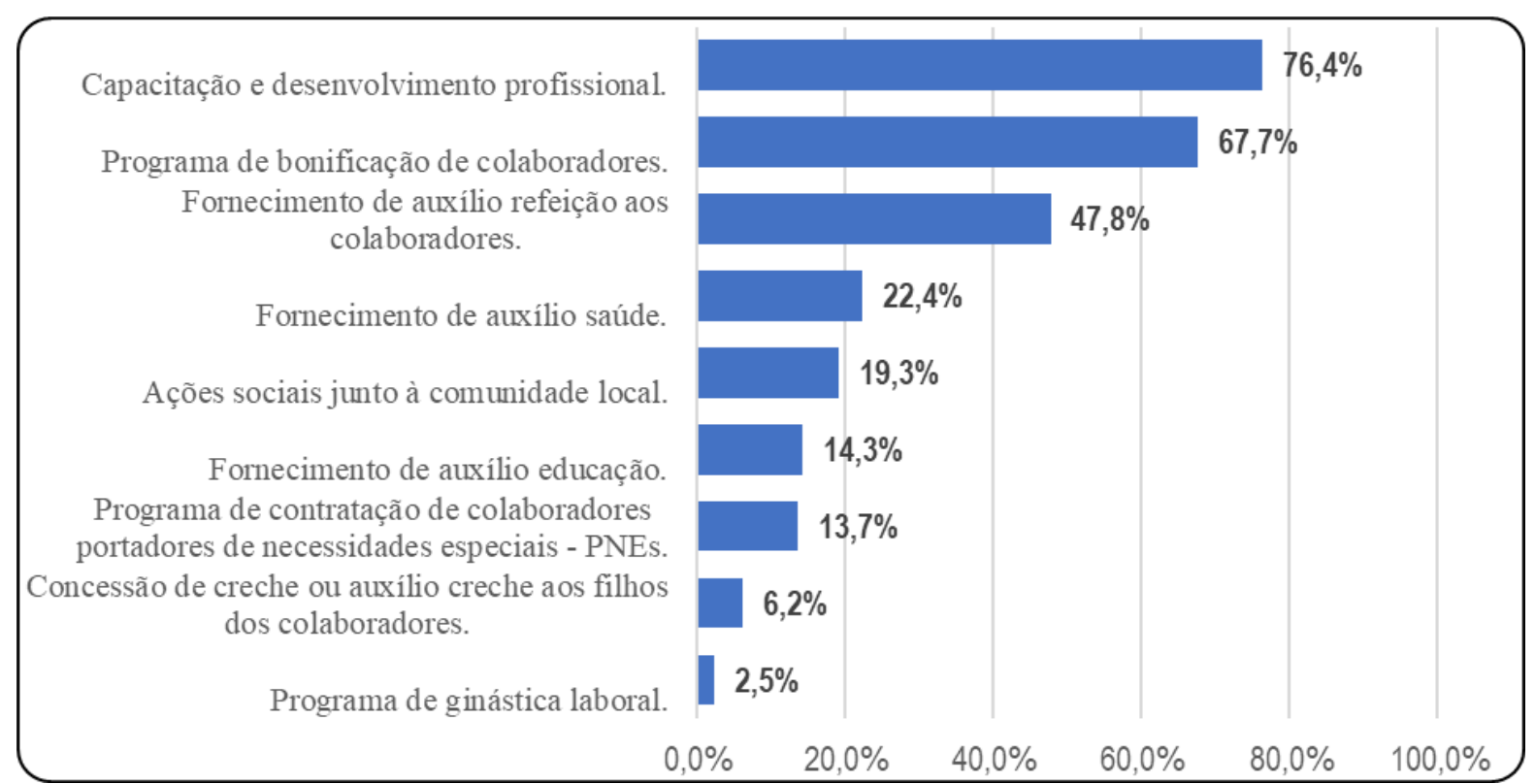

Figura 2. Práticas de gestão social

Fonte: Dados da pesquisa (2020)

Em seguida, tem-se a prática de bonificação de colaboradores com 67,7\% das empresas participantes. Essas bonificações estão associadas a recompensas, e, no caso das PMEs, impulsionam o aumento das vendas, a rotatividade de estoque e, consequentemente, maiores lucros. Sobre o fornecimento de auxílio refeição aos colaboradores, é importante destacar que, em muitos casos, a sua oferta é obrigatória, e, possivelmente por isso, essa prática aparece em terceiro lugar em $47,8 \%$ dos empreendimentos entrevistados, em contraponto, por exemplo, ao fornecimento de plano de saúde $(22,5 \%)$, benefício facultativo às empresas, o que possivelmente explica a baixa adesão, corroborando as observações já realizadas (Demajorovic \& Santiago; 2011; Paiva \& Giesta, 2019; Silva et al., 2020), que algumas práticas realizadas por MPEs são de cunho obrigatório movidas por legislações ambientais e outras são realizadas em razão de seu baixo custo de implantação, ficando, assim, as voluntárias e de maior custo com menor adesão (Silva, Santos \& Caetano, 2020; Bakos et al., 2019).

Resumindo, entre as práticas sociais, destacam-se a capacitação e o desenvolvimento profissional com 76,4\%; o programa de bonificação de colaboradores com $67,7 \%$ e o fornecimento de auxílio refeição aos colaboradores com 47,8\%. Entre as práticas sociais que requerem maior atenção por parte das empresas, têm-se o programa de contratação de colaboradores portadores de necessidades especiais - PNEs com 13,7\%, concessão de creche ou auxílio creche aos filhos dos colaboradores com $6,2 \%$ e programa de ginástica laboral com 2,5\%. Estes achados remetem ao que já foi relatado por Paiva \& Giesta (2019) de que as ações voltadas para as questões sociais são escassas e não estão relacionadas com as estratégias socioambientais, ou observado e sobre a importância dos governos federal, estaduais e municipais desenvolverem políticas de incentivos para que as pequenas empresas sejam estimuladas a adotar práticas de gestão social (Yakob \& Khor, 2019; Bakos et al., 2019).

A Figura 3 apresenta as práticas ambientais das PMEs. Entre as práticas ambientais adotadas, destaca-se a economia de energia elétrica com $85,7 \%$, o fornecimento/estímulo ao uso de caneca para beber água/cafezinho com 70,2\%, e empatados a coleta seletiva de lixo e a economia de água ou canalização de água da chuva na limpeza da empresa, com 50,9\%, cada, estes resultados estão alinhados a pesquisas nacionais e internacionais (Demajorovic \& Santiago, 2011; Font, Garey 
\& Jones, 2016; Paiva \& Giesta, 2019; Yacob \& Khor, 2019; Santos, Silva \& Caetano, 2020), nas quais ficou constatado que os pequenos empreendedores realizam práticas ambientais de baixo custo e/ou visando economizar recursos para a empresa. A limitação orçamentária de PMEs reduz sua capacidade de investimento em ações ambientais.

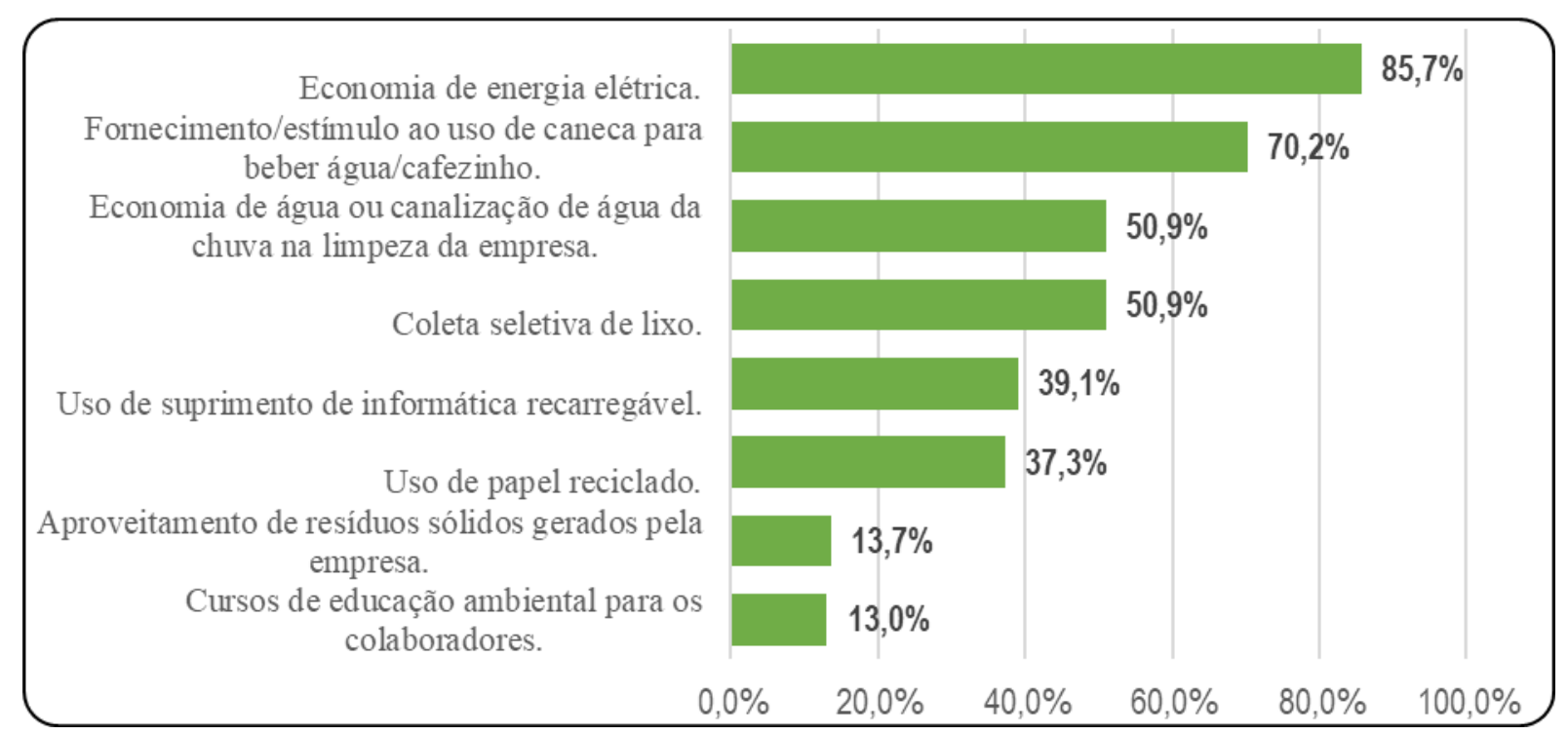

Figura 3. Práticas de gestão ambiental

Fonte: Dados da pesquisa (2020)

Assim, entre as práticas ambientais que requerem maior atenção estão o uso de papel reciclado com 37,3\%, o aproveitamento de resíduos sólidos gerados pela empresa com 13,7\% e os cursos de educação ambiental para os colaboradores com $13 \%$.

Assim, observa-se que a maioria das empresas entrevistadas realiza a gestão social dentro do que é obrigatório, para compliance às leis nacionais ou acordos sindicais, ou ainda como ponto de incentivo às vendas e lucros, como na bonificação sobre as vendas, com baixa adesão a tudo que foge da obrigatoriedade. Por sua vez, os resultados denotam que as empresas participantes da pesquisa estão inseridas no contexto da proteção ambiental, realizando ações ambientais com ênfase para as práticas que têm impacto direto na redução de custos e despesas, com ênfase na economia de energia elétrica.

\subsection{Importância atribuída, vantagens econômicas e políticas de incentivo governamentais}

De modo geral, os respondentes da pesquisa afirmaram que acreditam na importância de se desenvolver práticas de gestão socioambiental, equilibrando aspectos financeiros, sociais e ambientais, atendendo à stakeholders internos e externos. No entanto, entre os entrevistados, cerca de $50 \%$ afirmaram que não se reconhecem como poluidores, um percentual expressivo de comportamento, já avaliado em outras pesquisas (Arruda, 2016; Santos, Silva \& Caetano, 2020). Acreditar que as PMEs também são poluidoras é um ponto importante para que gestores trabalhem a gestão socioambiental de forma eficiente, PMEs não podem deixar essa responsabilidade somente para as grandes empresas, visto que o comprometimento é de todos (Aghelie, 2017).

Mas, quando instigados a opinar sobre as vantagens econômicas decorrentes da gestão socioambiental, concordam com a possibilidade de que pequenas empresas desenvolvam práticas socioambientais sem comprometer os lucros da empresa, dentre elas destacam-se a redução do consumo de água, energia e outros insumos, corroborando pesquisas anteriores (Kraemer, 2008; Aghelie, 2017; Paiva \& Giesta, 2019; Bakos et al., 2019). Reconhecem que produtos ecologicamente corretos podem obter vantagem competitiva e que, do contrário, a gestão de negócios sem consciência ambiental poderá provocar perda de oportunidades, podendo 
comprometer a manutenção e a longevidade dos negócios. Dessa forma, sócios proprietários e gerentes reconhecem que, com adoção da gestão socioambiental, é possível desenvolver estratégias, pela implantação de práticas socioambientais, que permitam as empresas vantagens econômicas, como já constatado em pesquisas anteriores, tais como em Martins, Escrivão Filho e Nagano (2015), Salvia, Pilonetto e Brandli (2016), Font, Garay e Jones (2016), Bakos et al., (2019), as quais evidenciaram a gestão socioambiental como um componente estratégico para a redução dos custos, busca de eficiência, melhoria da produtividade e da competitividade.

O terceiro aspecto da gestão socioambiental analisada trata das políticas de incentivo à adoção de práticas. Neste aspecto, empreendedores acreditam que os governos federal, estadual e municipal devem desenvolver políticas de incentivo, pleito já vislumbrado em pesquisas anteriores (Sanches \& Schimidt, 2016; Aghelie, 2017; Paiva \& Giesta, 2019), mas desconhecem se há normatização específica existente voltada ao incentivo às PMEs para que adotem uma gestão socioambiental. As PMEs participantes da pesquisa são sensíveis quando o assunto é imposto. A Lei do Simples Nacional, voltada para PMEs, já apresenta uma proposta diferenciada de apuração dos impostos, mas observa-se a manifestação dos interessados por mais incentivo físcal, isto é, que o governo possa criar tratamento diferenciado às empresas dedicadas a adotar e a implantar ações de natureza social e ambiental. A próxima etapa da pesquisa buscou associar o comportamento ao perfil dos respondentes.

\subsection{Associação do perfil sociodemográfico às práticas de gestão socioambiental}

Esta segunda etapa da pesquisa, de cunho exploratório, visou identificar associações entre o perfil dos entrevistados e as práticas e percepções sobre a gestão socioambiental. Assim, primeiramente, considerando a dimensão analítica das "práticas de gestão social", tendo como indicador de mensuração a "porcentagem $(\%)$ de utilização das práticas sociais", os testes indicaram que as únicas variáveis em que pelo menos uma de suas categorias possuem comportamento diferenciado (p-valor < 0,05), foram: "Cargo/função que desempenha atualmente na empresa" e "Porte da Empresa". As demais variáveis não se mostraram significativas, ou seja, não exerceram influência para a dimensão estudada.

Na sequência, considerando a dimensão analítica das "práticas de gestão ambiental", tendo como indicador de mensuração a "porcentagem (\%) de utilização das práticas ambientais", confirma-se que a única variável, em que pelo menos uma de suas categorias possui comportamento diferenciado ( $\mathrm{p}$-valor $<0,05$ ), é o "Cargo/função que desempenha atualmente na empresa". Esta variável possui apenas duas categorias (ou grupos), logo o Teste U de Mann-Whitney de amostras independentes foi o mais adequado, considerando um nível de significância de $5 \%(\alpha=0,05)$, assim rejeitando a hipótese de nulidade. As demais variáveis não se mostraram significativas, ou seja, não emitem influência para a dimensão estudada.

Ainda, buscou-se verificar a associação entre as variáveis sociodemográficas dos respondentes com as percepções acerca da importância da GSAE, suas vantagens econômicas e políticas de incentivo. Com base na percepção analítica que mensura o grau de concordância quanto à "Importância atribuída à adoção de práticas de gestão socioambiental", confirma-se que as únicas variáveis, em que pelo menos uma de suas categorias possui comportamento diferenciado ( $\mathrm{p}$-valor < 0,05), são: "Tempo de atuação na função que desempenha" e "Segmento de atividade sua empresa atua", assim rejeitando a hipótese de nulidade. As demais variáveis não se mostraram significativas, ou seja, não emitem influência para a dimensão estudada.

Considerando a dimensão de percepção analítica que mensura o grau de concordância quanto às "Vantagens Econômicas decorrentes da adoção de Práticas de Gestão Socioambiental", confirma-se que a única variável, em que pelo menos uma de suas categorias possui comportamento diferenciado ( $\mathrm{p}$-valor < 0,05), é o "Segmento de atividade que a empresa atua", assim rejeitando a hipótese de nulidade. As demais variáveis não se mostraram significativas, ou seja, não emitem influência para a dimensão estudada. 
Por fim, considerando a dimensão de percepção analítica que mensura o grau de concordância quanto à "Política de Incentivos a adoção de Práticas de Gestão Socioambiental", confirma-se que a única variável, em que pelo menos uma de suas categorias possui comportamento diferenciado ( $\mathrm{p}$-valor < 0,05), é o "Segmento de atividade sua empresa atua", assim rejeitando a hipótese de nulidade. As demais variáveis não se mostraram significativas, ou seja, não emitem influência para a dimensão estudada. A Tabela 6 sumariza os resultados das associações realizadas.

Tabela 6. Associação entre as ações e percepções em GSAE e o perfil sociodemográfico

\begin{tabular}{|c|l|}
\hline $\begin{array}{c}\text { Bloco de } \\
\text { resultados }\end{array}$ & \multicolumn{1}{|c|}{ Dimensões de análises } \\
\hline Bloco 01 & Práticas de gestão social nas PMEs \\
\hline Bloco 02 & Práticas de gestão ambiental nas PMEs \\
\hline Bloco 03 & $\begin{array}{l}\text { Importância atribuída à adoção de } \\
\text { práticas de gestão socioambiental }\end{array}$ \\
\hline Bloco 04 & $\begin{array}{l}\text { Vantagens econômicas decorrentes da } \\
\text { adoção de práticas de GSAE }\end{array}$ \\
\hline Bloco 05 & $\begin{array}{l}\text { Política de incentivos a adoção de } \\
\text { práticas de gestão socioambiental. }\end{array}$ \\
\hline
\end{tabular}

Fonte: Dados da pesquisa (2020)

Os resultados desta etapa exploratória sugerem que o cargo desempenhado, o tempo de atuação e o porte da empresa possuem associação com o desenvolvimento de ações de responsabilidade socioambiental, indicando que proprietários-gerentes com maior tempo de atuação e estruturação de seus empreendimentos apresentam maior propensão à realização das práticas ambientais. Os mesmos resultados a que Silva et al. (2020) chegaram, sinalizando que a maturidade, na formação acadêmica e o tempo de atuação levam a uma maior sensibilidade com as causas socioambientais. Em outra mão, os resultados corroboraram a pesquisa de Pereira et al., (2013) os quais observaram que o porte das empresas está associado a uma melhor adequação às práticas de gestão socioambiental, provavelmente provocado, por um lado, pelo aumento de pressão social e legal, e por outro, pela folga financeira obtida na medida do crescimento do empreendimento.

De modo geral, as PMEs participantes desta pesquisa denotaram, como em pesquisas anteriores (Sousa et al., 2014; Martins et al., 2015; Sanches \& Schimidt, 2016; Paiva \& Giesta (2019); Schott \& Vasconcelos (2019); Yacob \& Khor (2019); Santos, Silva \& Caetano (2020), a ausência de estratégias para a realização sistemática de uma gestão socioambiental organizacional.

Cabe ressaltar que, devido à grande concentração de respondentes do setor de comércio, não se considerou o setor como um elemento significativo para a associação com a percepção dos gestores acerca da importância atribuída, vantagens econômicas e políticas de incentivo. Do contrário, este ponto de análise se apresentou como uma limitação da pesquisa, no entanto, sem prejudicar outras análises realizadas.

\section{CONSIDERAÇÕES FINAIS}

A análise dos resultados demonstrou que, em geral, as PMEs promovem, com grau variado de intensidade, ações de natureza social e ambiental, ainda sem uma estratégia subjacente ou sistematização de ações que extrapolem a ênfase em objetivos econômicos de redução de custos e despesas e/ou para atendimento a legislação vigente. Sob o aspecto social, destacam-se, em ordem decrescente de incidência, as práticas de implementação de programas de capacitação e desenvolvimento profissional, o programa de bonificação e o fornecimento de auxílio refeição aos colaboradores. De outra banda, as práticas ambientais de maior incidência entre os entrevistados correspondem, também, sob uma escala decrescente, à economia de energia elétrica, o 
fornecimento/estímulo ao uso de caneca para beber água/cafezinho, a coleta seletiva de lixo e a economia de água ou canalização de água da chuva para limpeza. Como já discutido, seguindo uma tendência já documentada em pesquisas prévias, como em outras PMEs estabelecidas nas demais regiões do Brasil e do mundo, de realizar práticas que atendam a legislação vigente, ou ainda que representem redução de custos e/ou possibilidade de algum ganho ou melhora do resultado da organização.

De modo geral, ainda que tenham afirmado que não se reconhecem como poluidores, gestores acreditam na importância de desenvolver práticas de gestão socioambiental, equilibrando aspectos financeiros, sociais e ambientais, atendendo à stakeholders internos e externos, desde que dentro de parâmetros que não comprometam os lucros da empresa. Nesse sentido, acreditam que os governos federal, estadual e municipal devem desenvolver políticas de incentivo para que PMEs desenvolvam ações socioambientais, mas desconhecem se há normatização específica existente voltada ao segmento de empresas.

Além disso, os resultados da pesquisa evidenciaram que, diante da dimensão analítica das práticas de gestão social, apenas as variáveis sociodemográficas cargo desempenhado, o tempo de atuação e o porte da empresa guardam relação significativa com as práticas socioambientais percebidas como importantes e realizadas pelas empresas participantes da amostra, de modo muito interessante a resultados similares já encontrado em outras pesquisas

Conclui-se que a gestão socioambiental pode ser utilizada como instrumento de aperfeiçoamento para PMEs e que, no campo da ciência, é relevante e inovador desenvolver e divulgar pesquisas para as organizações, empreendedores, gerentes e colaboradores, para que a temática socioambiental possa cada vez mais fazer parte do dia a dia dos cidadãos e assim as práticas socioambientais possam transcender os muros das organizações, chegando também às comunidades, aos clientes, fornecedores e demais stakeholders. Dessa forma, estima-se que todos envolvidos no processo sairão ganhando com a junção de esforços de todos que tiverem relação direta e indireta com a organização, bem como o meio ambiente.

A relevância deste estudo pode ser evidenciada por ser um dos primeiros trabalhos voltados para o levantamento da gestão socioambiental conduzidos no estado do Pará, notadamente, e de forma abrangente, capturando não apenas as práticas, mas explorando também a percepção dos gestores de PMEs em "três novos pilares" de análise, quais sejam, a importância atribuída, a percepção de vantagem econômica e a discussão sobre o incentivo governamental. Os resultados apontam implicações amplas para todas as PMEs, molas propulsoras de economias em desenvolvimento, como o Brasil, onde o desenvolvimento das pequenas empresas com sustentabilidade certamente tem implicações positivas no desenvolvimento econômico do país.

Para pesquisas futuras, pode ser dado ênfase às políticas de apoio do governo para ações socioambientais em PMEs, sugere-se que novas pesquisas sejam realizadas e até mesmo ferramentas sejam desenvolvidas para auxiliar no desenvolvimento da gestão socioambiental das PMEs. Pode-se sugerir a ampliação da pesquisa para outras localidades (cidades/estados) com o intuito de obter uma amostra mais robusta, permitindo uma análise mais ampla de suas práticas e a importância da GSAE para o aperfeiçoamento da gestão organizacional das PMEs. O relato de casos de sucesso de PMEs já comprometidas com a gestão socioambiental para divulgação e incentivo também são pontos importantes a serem pesquisados no futuro, haja vista a necessidade de estimular a adoção de práticas.

\section{REFERÊNCIAS}

Aghelie, A. (2017). Exploring drivers and barriers to sustainability green business practices within small medium sized enterprises: primary findings. International Journal of Business and Economic Development (IJBED), 5(1). 
Andrade, R. O. B. D., Tachizawa, T., \& Carvalho, A. B. D. (2002). Gestão ambiental: enfoque estratégico aplicado ao desenvolvimento sustentável. In Gestão ambiental: enfoque estratégico aplicado ao desenvolvimento sustentável. São Paulo. Pearson Markron Books.

Arruda, C. D. (2016). A sustentabilidade sob a ótica de mulheres empreendedoras do oeste catarinense. EGEPE-Encontro de Estudos Sobre Empreendedorismo e Gestão de Pequenas Empresas, 9.

Bakos, J., Siu, M., Orengo, A., \& Kasiri, N. (2019). An analysis of environmental sustainability in small \& medium-sized enterprises: Patterns and trends. Business Strategy and the Environment, 29(3), 1285-1296.

Barbosa, J. D., \& Teixeira, R. M. (2001). Apesar dos pesares, vale a pena ser pequeno empresário? Traçando perfil e descobrindo motivos. EGEPE-Encontro de Estudos sobre Empreendedorismo e Gestão de Pequenas Empresas, 1.

Barbieri, J. C. (2007). Gestão ambiental empresarial: conceitos, modelos e instrumentos. São Paulo: Saraiva.

Bossle, M. B. (2008). Responsabilidade socioambiental em pequenas empresas de serviços.

Brasil. Lei Complementar $n^{\circ}$ 123, de 14 de dezembro de 2006. Porto Alegre. Universidade Federal do Rio Grande do Sul.

Cordano, M., Marshall, R. S., \& Silverman, M. (2010). How do small and medium enterprises go "green"? A study of environmental management programs in the U.S. wine industry. Journal of Business Ethics, 92(3), 463-478.

Deitos, M. L. M. S. (2002). A gestão da tecnologia em pequenas e médias empresas: fatores limitadores e formas de superação. Cascavel: Edunioeste - coleção Thésis.

Demajorovic, J., \& Santiago, A. L. F. (2011). Responsabilidade socioambiental na micro e pequena empresa: práticas e desafios. Gestão.org, 2(9), 254-281.

Donaire, D. (1995). Gestão ambiental na empresa. São Paulo: Atlas.

Farias Filho, M. C., \& Arruda Filho, E. J. M. (2013). Planejamento da pesquisa científica. São Paulo: Atlas.

Ferronato, A. J. (2011). Gestão contábil-financeira de micro e pequenas empresas: sobrevivência e sustentabilidade. São Paulo: Atlas.

Font, X., Garay, L., \& Jones, S. (2016). Sustainability motivations and practices in small tourism enterprises in European protected areas. Journal of Cleaner production, 137, 1439-1448.

Freeman, R. E. (1984). Strategic management: a stakeholder approach. Boston: Pitman.

Karkotli, G. R., Ferreira, E. \& Souza, M. J. B. de. (2005). Responsabilidade social: uma estratégia Empreendedora para pequenas empresas. Egepe-Encontro de Estudos sobre Empreendedorismo e Gestão de Pequenas Empresas, 4.

Kraemer, M. E. P. (2008). Gestão ambiental: um enfoque no desenvolvimento sustentável. Recuperado em: 30/03/2020, de: https://sanambiental.blogspot.com/2008/08/gesto-ambiental-um-enfoque-no.html.-

Lopes, A. I. G., \& Barbosa, M. D. F. N. (2021). Gestão socioambiental no setor de laticínios no Município de Sousa-Paraíba. Brazilian Journal of Development, 7(3), 32083-32102.

Martins, P. S., Escrivão Filho, E., \& Nagano, M. S. (2015). Gestão ambiental e estratégia empresarial em pequenas e médias empresas: um estudo comparativo de casos. Engenharia Sanitária e Ambiental, 20(2), 225-234. 
Moysés Filho, J. E., Rodrigues, A. L., \& Moretti, S. L. A. (2011). Gestão social e ambiental em pequenas e médias empresas: influência e poder dos stakeholders. Revista Eletrônica de Administração, 17, 204-236.

Nogueira, M. da G. S. (2012). Instituição de ensino superior: uma visão sobre a responsabilidade social corporativa pública como ferramenta de vantagem competitiva e estratégia de expansão. Egepe-Encontro de Estudos Sobre Empreendedorismo e Gestão de Pequenas Empresas, 7.

Oliveira, M. D. A. S., \& Rossetto, A. M. (2014). Influência dos fatores externos na decisão estratégica em sustentabilidade nas pequenas empresas hoteleiras. Egepe-Encontro de Estudos Sobre Empreendedorismo e Gestão de Pequenas Empresas, 8.

Paiva, F. C. D. S., \& Giesta, L. C. (2019). Gestão socioambiental em micro e pequenas indústrias de Pau dos Ferros-RN. Gestão \& Produção, 26.

Passos, L. A. N. \& Camara, M. R. G. (2003). Evolução da gestão ambiental em empresas industriais: um estudo nas pequenas e médias empresas do setor químico Egepe-Encontro de Estudos Sobre Empreendedorismo e Gestão de Pequenas Empresas, 3.

Pereira, M. A. V., \& Moreira, M. A. (2018). Análise bibliométrica sobre práticas de gestão socioambiental na pequena empresa. P2P e Inovação, 5(1), 177-194.

Pereira, A. C., de Melo, S. B., Slomski, V. G., \& Weffort, E. F. (2013). Percepções de gestores sobre as contribuições do processo de certificação ISO 14001 nas práticas de gestão ambiental. Revista de Contabilidade e Organizações, 7(17), 69-88.

Salvia, A. L., Pilonetto, I \& Brandli, L. (2016). Desafios na aplicação da sustentabilidade no setor elétrico brasileiro. EGEPE-Encontro de Estudos sobre Empreendedorismo e Gestão de Pequenas Empresas, 9.

Sammut, S. (2001). Le processus de démarrage em petite enterprise: sistème de gestion et scénarios. Revue del'Entrepreneuriat, 1(1), 61-76.

Sanches, F. C. \& Schimidt, C. M. (2016). Indicadores de Sustentabilidade Ambiental: uma análise das práticas sustentáveis em empreendimentos de turismo rural. EGEPE-Encontro de Estudos Sobre Empreendedorismo e Gestão de Pequenas Empresas, 9.

Sanches, C. S. (2000). Gestão ambiental proativa. Revista de Administração de Empresas, 40(1), 76-87.

Santos, E. C., Silva, J. K. L., \& Caetano, R. M. (2020). As práticas de sustentabilidade e de responsabilidade social aplicadas nas micro e pequenas empresas e em microempreendedores individuais de VilhenaRo. Revista de Administração e Negócios da Amazônia, 11(4), 1-20.

Savitz, A. W. (2007). A empresa sustentável: o verdadeiro sucesso é lucro com responsabilidade social e ambiental. Rio de Janeiro: Elsevier.

Scharf, E. R., Fernandes, J., \& Orlandi, O. (2013). Gestão Ambiental como Estratégia de Marketing em uma Empresa de Turismo Rural. Turismo-Visão e Ação, 15(2), 226-243.

Schott, G. L. M., \& Vasconcelos, F. C. W.(2019) Práticas de gestão socioambiental nas indústrias de confecção do vestuário para implementação da Política Nacional De Resíduos Sólidos. Congresso Brasileiro de Gestão Ambiental, 10.

Sebrae. Serviço Brasileiro de Apoio às Micro e Pequenas Empresas. (2014). Anuário do Trabalho na Micro e Pequena Empresa.

Sebrae. Serviço Brasileiro de Apoio às Micro e Pequenas Empresas. (2015). Sustentabilidade: boletim de tendências. 
Sebrae. Serviço Brasileiro de Apoio às Micro e Pequenas Empresas. (2018). Perfil das pequenas empresas e empresas de pequeno porte.

Seravalli, V. (2018). Responsabilidade social empresarial. CIESP. Recuperado em: 30/03/2020 de: <https://www.fiesp.com.br/indices-pesquisas-e-publicacoes/artigo-vitor-seravalli/>.

Shuman, J. C., Shaw, J. J., \& Sussman, G. (1985). Strategic planning in smaller rapid growth companies. Long range planning, 18(6), 48-53.

Silva, M., Theis, V., Schreiber, D., \& Figueiro, P. S. (2020). Análise da percepção dos colaboradores quanto às práticas socioambientais em uma indústria pet food. Reunir Revista de Administração Contabilidade e Sustentabilidade, 10(3), 86-95.

Sousa, A. M. R., Rabêlo Neto, A. R., Silva, A. S. L., Bezerra, E. P., \& Ribeiro, R. M. (2014). Educação ambiental: o que pensam os alunos? O que faz a IES. Engema - Encontro Internacional sobre Gestão Ambiental e Meio Ambiente, 16.

Stumpf, U. D., Theis, V., \& Schreiber, D. (2018). Gestão de resíduos sólidos em empresas metalomecânicas de pequeno porte. Revista de Gestão Ambiental e Sustentabilidade: GeAS, 7(2), 230-247.

Tachizawa. T. (2010). Gestão ambiental e responsabilidade social corporativa: estratégias de negócios focadas na realidade brasileira. São Paulo: Atlas.

Tenório, F. G. (2006). Responsabilidade social empresarial: teoria e prática. Rio de Janeiro: FGV.

Tinoco, J. E. P., \& Kraemer, M. E. P. (2011). Contabilidade e gestão ambiental (3ª Edição). São Paulo: Atlas.

Trindade, J. D. (2012). Gestão Socioambiental no consumo responsável no empreendedorismo sustentável. Egepe-Encontro de Estudos sobre Empreendedorismo e Gestão de Pequenas Empresas, 7.

Walsh, J. A., White, J. F., \& Dowell, P. (1981). A small business is not a little big business. Harvard Business Review, 59(4), 18-32.

Yacob, P., Wong, L. S., \& Khor, S. C. (2019). An empirical investigation of green initiatives and environmental sustainability for manufacturing SMEs. Journal of Manufacturing Technology Management.

\section{Como citar:}

Viana Pereira, M. A., Moreira, M. A., Martins, C. M., \& da Costa de Moura, B. V. (2021). Gestão Socioambiental em Pequenas e Médias Empresas. Revista De Gestão Social E Ambiental, 15, e02731. https://doi.org/10.24857/rgsa.v15i2.2731 